\title{
Criptógamos do Parque Estadual das Fontes do Ipiranga, São Paulo, SP. Algas, 31: Euglenophyceae (Euglenaceae não-pigmentadas)
}

\author{
Carlos Eduardo de Mattos Bicudo ${ }^{1}$
}

Recebido: 18.03.2010; aceito: 30.12.2010

\begin{abstract}
Cryptogams of the "Parque Estadual das Fontes do Ipiranga", São Paulo, SP. Algae, 31: Euglenophyceae (non-pigmented Euglenaceae). Taxonomic survey of representatives of non-pigmented forms of family Euglenaceae (Euglenophyceae) in the Parque Estadual das Fontes do Ipiranga, São Paulo, Brazil. Three genera (Acusmonas, Gyropaigne and Menoidium) and three species (one of each genus) were identified. All species were collected from a single locality each.
\end{abstract}

Key words: Brazil, Euglenophyceae, floristic survey

RESUMO - (Criptógamos do Parque Estadual das Fontes do Ipiranga, São Paulo, SP. Algas. 31: Euglenophyceae (Euglenaceae não-pigmentadas). Levantamento florístico dos representantes não-pigmentados da família Euglenaceae (Euglenophyceae) do Parque Estadual das Fontes do Ipiranga, São Paulo, Brasil. Três gêneros (Acusmonas, Gyropaigne e Menoidium) e três espécies (uma de cada gênero) foram identificados. Cada espécie ocorreu somente em uma localidade.

Palavras-chave: Brasil, Euglenophyceae, levantamento florístico

\section{Introdução}

Os representantes não-pigmentados das Euglenophyceae têm recebido bastante menos atenção por parte dos especialistas em âmbito mundial do que as formas pigmentadas. Este fato também é verdade quando se trata do conhecimento da ficoflórula do PEFI, Parque Estadual das Fontes do Ipiranga, em São Paulo.

O conhecimento das formas não-pigmentadas de Euglenaceae do PEFI está contido em apenas duas publicações. A primeira é de Skvortzov (1969) que identificou 28 gêneros e 31 espécies após estudar material coletado nas cidades de São Paulo no Brasil e Harbin na China, os quais foram classificados na família Astasiaceae. Do total identificado, 23 gêneros e 25 espécies foram descritos e propostos como novos para a Ciência e, dentre estes, para o PEFI os gêneros Acusmonas e Eneidamonas com uma espécie cada um: A. pluvialis Skvortzov e E. applanata Skvortzov, respectivamente. Os materiais estudados foram coletados de um ambiente temporário, isto é, de uma depressão preenchida com água de chuva e de um ambiente com água contaminada (impura no dizer de Skvortzov 1969), as duas localidades situadas no PEFI.

A segunda publicação é de Bicudo \& Bicudo (1987), que noticiaram a ocorrência de quatro espécies de Euglenophyceae na cidade de São Paulo e arredores, a saber: Phacus ephippioideus C. Bicudo $\&$ D. Bicudo (forma pigmentada) e Gyropaigne brasiliensis C. Bicudo \& D. Bicudo, Scytomonas major (Berliner) Lemmernann e Scytomonas pusilla Stein var. sarmatica Drezepolski (formas não-pigmentadas). Gyropaigne brasiliensis C. Bicudo \& D. Bicudo foi proposta como nova para a Ciência nesse último trabalho, a partir de material coletado no hidrofitotério do Jardim Botânico de São Paulo, Parque Estadual das Fontes do Ipiranga.

O objetivo do presente trabalho foi reunir e revisar toda a informação sobre as euglenáceas despigmentadas que ocorrem no PEFI. Essa informação consta do material citado nos dois trabalhos publicados, que constituem toda a literatura existente; e do estudo do material coletado durante pouco mais de 40 anos em ambientes lóticos (riachos) e semi-lênticos (represas) existentes na área do PEFI.

1. Instituto de Botânica, Caixa Postal 68041, 04045-972 São Paulo, SP, Brasil. E-mail: cbicudo@terra.com.br 


\section{Material e métodos}

Como sucedeu anteriormente, o presente trabalho foi baseado quase que inteiramente em material da literatura. Exceto Gyropaigne brasiliensis C. Bicudo $\&$ D. Bicudo, que foi originalmente coletado no Jardim Botânico de São Paulo e posteriormente coletado de novo na mesma localidade, todas as amostragens recentes realizadas na área do PEFI jamais contiveram material de Euglenaceae não-pigmentadas. Os espécimes de G. brasiliensis C. Bicudo \& D. Bicudo não foram fixados nem preservados pelos métodos usualmente empregados para tanto. Dessa forma, não há material dessa espécie e de nenhuma outra incluída neste trabalho que tenha sido depositado no Herbário Científico do Estado "Maria Eneyda P. Kauffmann Fidalgo" (SP) do Instituto de Botânica da Secretaria do Meio Ambiente do Estado de São Paulo.

Para a pronta localização dos gêneros neste trabalho, eles foram relacionados em ordem alfabética crescente. As espécies que só constam da literatura, ou seja, que não foram reencontradas durante a presente pesquisa, foram relacionadas nas chaves de identificação e no texto precedidas por um asterisco.

O sistema de classificação ora adotado é o que consta em Bourrelly (1985), por ser o único que inclui quase todos os gêneros conhecidos até o presente e classificados pelo referido autor segundo critérios uniformemente aplicados a todo o universo dos gêneros nele contidos.

\section{Resultados e Discussão}

Os três gêneros presentemente identificados para o PEFI têm a seguinte situação sistemática:

Divisão Euglenophyta

Classe Euglenophyceae

Ordem Euglenales

Família Euglenaceae

Acusmonas

Gyropaigne

Menoidium

\section{EUGLENACEAE}

A família inclui indivíduos unicelulares, de hábito isolado, vida livre e ativamente móveis, porém, pouco metabólicos na fase vegetativa de seu histórico-devida. Possuem dois flagelos inseridos anteriormente na célula, no fundo da citofaringe. Esses flagelos possuem tamanhos bastante diferentes entre si, sendo que o maior emerge da citofaringe e está voltado para frente enquanto o indivíduo se desloca e o menor é reduzido a um simples coto que apenas vibra no interior da citofaringe. A maioria dos representantes desta família não possui pigmento, mas ocorrem sete gêneros pigmentados. Nestes casos, os plastídios são usualmente numerosos, possuem forma mais ou menos discóide e localização parietal na célula. Raramente ocorrem um ou dois plastídios de forma laminar e situação também parietal na célula. A película é sempre bastante delgada, permite metabolia e pode ser lisa ou decorada com estrias que podem, por sua vez, ser longitudinais ou torcidas em hélice. As formas pigmentadas possuem estigma, mas as incolores não. Os espécimes despigmentados são saprófitas ou parasitas e os pigmentados autotróficos.

\section{Acusmonas Skvortzov}

Indivíduos unicelulares não metabólicos, de vida livre e hábito solitário livre-natante. A célula é mais ou menos fusiforme, às vezes quase acicular e tem a seção transversal sempre circular. O pólo anterior é repentinamente afilado, com a extremidade acuminada; o pólo posterior é gradualmente afilado para a extremidade pontiaguda. Aparentemente, ocorre só um flagelo inserido apicalmente na célula, que mede desde $2 / 3$ até todo o comprimento da célula; e que vibra só na sua extremidade livre. A película é bastante delicada e lisa. Não foram observados citofaringe, estigma, vacúolos contráteis e grãos de paramido.

Bicudo \& Menezes (2006) consideraram Acusmonas idêntico a Menoidiomonas Skvortzov (1958), afirmando que o primeiro difere do segundo apenas por não possuir grãos de paramido. Os exemplares de A. pluvialis Skvortzov não possuem citofaringe, ou seja, característica diagnóstica dos representantes da família Euglenaceae. Também, aparentemente, possuem apenas um flagelo que só vibra em sua extremidade livre, no que diferem das demais Euglenaceae, cujo flagelo é inteiramente vibrátil. Estas duas características colocam em dúvida a situação de Acusmonas entre as Euglenaceae e, provavelmente, o situe entre as Peranemaceae. Optou-se então, neste trabalho, por manter o gênero Acusmonas independente de Menoidiomonas até que se amplie o conhecimento da morfologia dos espécimes do primeiro.

Uma única espécie foi identificada. 
*A. pluvialis Skvortzov, Q. Journ. Taiwan Mus. 22(3-4): 231, pl. 1, fig. 15. 1969.

Figura 1

Indivíduo unicelular, solitário, livre-natante, pouco metabólico; célula mais ou menos fusiforme até quase acicular, pólo anterior repentinamente afilado, extremidade acuminada, pólo posterior gradualmente afilado, extremidade pontiaguda, seção transversal circular, 37-45 $\mu \mathrm{m}$ compr., 2-3,6 $\mu \mathrm{m}$ larg.; flagelo 1 , 0,6-1 vez o comprimento total da célula, vibrátil só na extremidade; película delicada, lisa.

Hábitat: planctônico.

Tudo o que se sabe sobre esta espécie é o que consta em sua descrição original em Skvortzov (1969), que estudou material coletado de um ambiente temporário, isto é, de uma depressão preenchida com água de chuva no PEFI. Esse trabalho contém as proposições do gênero e de sua única espécie: A. pluvialis Skvortzov.

Segundo Bicudo \& Menezes (2006), o gênero Acusmonas difere de Menoidiomonas unicamente pela ausência de grãos de paramido, desde que o último possui numerosos grãos de forma anelar e o primeiro não tem tais grânulos. Skvortzov (1969) examinou, ao que tudo indica, vários exemplares desta espécie, mas a informação que apresentou da população estudada é bastante precária. Primeiramente, falta no comentário original em Skvortzov (1969) informação suficiente para a própria classificação do gênero entre as Euglenaceae. Em seguida, essa informação também é insuficiente para definir se Acusmonas é um gênero independente ou se deve ser considerado idêntico a Menoidiomonas, isto é, um sinônimo heterotípico deste último. Consideramos ser mais prudente, por enquanto, manter o gênero Acusmonas independente e A. pluvialis Skvortzov uma espécie bem circunscrita, até que mais se conheça sobre sua morfologia.

\section{Gyropaigne Skuja}

Indivíduos unicelulares não-metabólicos, livrenatantes e hábito solitário. A forma da célula em repouso pode ser elipsóide, obovóide, fusiforme ou curto-cilíndrica. A seção transversal da célula é radiada, às vezes um pouco achatada, porém, sempre com saliências e depressões periféricas. A película é firme, lisa e possui saliências longitudinalmente dispostas ou torcidas em hélice em vista frontal. Ao que tudo indica, ocorre, apenas um flagelo inserido no fundo da citofaringe, cuja abertura é levemente subapical. Os grãos de paramido são numerosos e aparecem mais ou menos uniformemente dispersos no citoplasma.

Existe certa controvérsia quanto à situação taxonômica de Gyropaigne. Os autores concordam, de modo geral, com sua classificação na família Astasiaceae (exemplo Huber-Pestalozzi 1955), porém, Leedale (1967) o situou entre as Rhabdomonadales e Bourrelly (1985) entre as Euglenaceae. De fato, embora o gênero possua ao redor de cinco espécies já descritas, o fato é que todas foram raramente encontradas e são conhecidas, praticamente, só por suas descrições originais. Não se sabe ainda se existe um segundo flagelo, muito pequeno, que permaneceria vibrando no interior da citofaringe, como em Euglena, por exemplo, e que justificaria sua situação entre as Euglenaceae. Sua classificação entre as Astasiaceae é devida a uma característica negativa, qual seja: a ausência de bastonete faringeano. Esta característica não é boa, entretando, por ser negativa e não constitui boa prática definir através da ausência. Sua classificação, finalmente, na ordem Rhabdomonadales é devida à existência de um único flagelo, fato este ainda não comprovado, mas, apenas sugerido. Leedale (1967) sugeriu que caso seja provado que alguma das espécies de Gyropaigne possua um segundo flagelo não-emergente do reservatório, que essa espécie deveria ser colocada numa ordem separada sem, entretanto, identificar qual seria essa ordem.

Uma única espécie foi identificada.

G brasiliensis C. Bicudo \& D. Bicudo, Acta Bot. Bras. 1(1): 44, fig. 7-9. 1987.

Figuras 2-4

Indivíduo unicelular, solitário, livre-natante, não metabólico; célula em repouso elipsóide, assimétrica, pólo anterior levemente acuminado ou truncadoarredondado, pólo posterior acuminado, 37-45 $\mu \mathrm{m}$ compr., 18-22 $\mu \mathrm{m}$ larg.; flagelo 1 , inserido subapicalmente; citofaringe bem marcada, estigma ausente, vacúolo contrátil não observado, grânulos de paramido 8-10, distribuídos mais ou menos uniformemente por toda a célula; película firme, longitudinalmente carenada, carenas 8 ; seção transversal aproximadamente elíptica, 8-carenada.

Hábitat: planctônico.

Todo o conhecimento presente sobre G. brasiliensis C. Bicudo \& D. Bicudo está em sua descrição original em Bicudo \& Bicudo (1987) e em uma coleta posterior efetuada no mesmo ambiente. 
O material que serviu de base para a descrição e proposição da espécie foi coletado no hidrofitotério do Jardim Botânico de São Paulo e foi bastante rico em espécimes. O flagelo é caduco e, por isso, de difícil observação. Em alguns exemplares pôde ser observado subapicalmente na célula, porém, não seu tamanho em relação ao comprimento da célula.

O formato elipsóide e nitidamente assimétrico de seus representantes em vista frontal e sua seção transversal pouco até marcadamente comprimida (elíptica) são as características que separam G. brasiliensis C. Bicudo \& D. Bicudo de todas as demais quatro espécies do gênero.

\section{Menoidium Perty}

Indivíduos unicelulares, livre-natantes, não metabólicos, de hábito solitário. A célula tem forma lunada bastante característica, semelhante à de uma banana, com uma das margens (dorsal) amplamente convexa e a outra (ventral) variável desde pouco até marcadamente côncava. O pólo anterior é mais afilado que o posterior e chanfrado em bisel (truncadoinclinado). A seção transversal da célula é aproximadamente circular. A película é firme e longitudinal (raro) ou helicoidalmente (em geral) estriada. Ocorrem dois flagelos inseridos no fundo da citofaringe, cuja abertura é apical. Um desses flagelos extravasa a citofaringe e o outro, de tamanho muito menor que o primeiro, jaz vibrando no interior da citofaringe. Os grãos de paramido são poucos, mais ou menos cilíndricos e estão localizados tanto na parte anterior quanto na posterior da célula.

Uma única espécie foi identificada.

*M. pellucidum Perty, Zur Kenntnis kleinster Lebens-formen nach Bau, Funktionen, Systematik, mit Specialverzeichnis der in der Schweiz beobachteten. 174, pl. 15, fig. 19-26. 1852.

Figura 5

Indivíduo unicelular, solitário, livre-natante, não metabólico; célula aproximadamente lunada, margem dorsal amplamente convexa, margem ventral acentuadamente côncava, pólo anterior truncadoinclinado, mais afilado que o posterior, pólo posterior arredondado, ca. 66,1 $\mu \mathrm{m}$ compr., ca. 17,7 $\mu \mathrm{m}$ larg.; flagelos 2, inseridos apicalmente no fundo da citofaringe, tamanhos extremamente diferentes entre si; grânulos de paramido poucos, mais ou menos cilíndricos, restritos à parte anterior da célula; seção transversal subcircular; película firme, longitu- dinalmente estriada.

Hábitat: planctônico.

Segundo Huber-Pestalozzi (1955), existem 16 espécies descritas de Menoidium. O material coletado no PEFI aproxima-se, morfologicamente, de duas delas, quais sejam: M. pellucidum Perty e M. aspera Huber-Pestalozzi. Difere, contudo, da última por possuir película lisa, destituída de diminutos grânulos ou espinhos que conferem aspereza à película de M. aspera Huber-Pestalozzi e valeram, inclusive, seu epíteto específico. O material do hidrofitotério difere de $M$. pellucidum Perty apenas no número de grânulos de paramido, que a literatura refere com sendo dois, mas que encontramos quatro. Considerando, entretanto, que $M$. pellucidum Perty é conhecido apenas por sua descrição original e que o número de grânulos de paramido pode variar em uma mesma espécie, não vimos razão para não identificar o presente material, embora representado por um pequeno número de indivíduos, com os representantes de $M$. pellucidum Perty. O material ilustrado em Bicudo \& Menezes (2006) proveio do hidrofitotério do Jardim Botânico de São Paulo. A seção transversal praticamente circular da célula foi observada em todos os exemplares examinados, enquanto se deslocavam, porém, não foi possível ilustrá-la.

Embora o esforço de coleta na área do PEFI já ultrapasse 40 anos e tenha sido bastante intenso, quase nenhum material de Euglenaceae despigmentadas foi reencontrado. Por conseguinte, todo o conhecimento de Acusmonas pluvialis Skvortzov e Menoidium pellucidum Perty neste trabalho provém de suas descrições originais, que constituem os únicos documentos disponíveis sobre essas duas espécies. Como foi dito em outras ocasiões, as descrições dos materiais na literatura são bastante precárias e incompletas por estarem baseadas em alguns poucos exemplares (Acusmonas pluvialis Skvortzov) ou em um único espécime (Menoidium pellucidum Perty). Consideramos, entretanto, que os nomes dessas duas espécies devem prevalecer até que mais material de cada uma seja coletado e estudos mais aprofundados realizados, permitindo um conhecimento mais detalhado e adequado de cada uma.

As Euglenaceae despigmentadas são organismos que habitam, de preferência, os sedimentos, de onde retiram a matéria orgânica para sua nutrição. Os materiais coletados por B.V. Skvortzov provieram de ambientes descritos de maneira muito vaga, tão vaga que sua localização se torna, na prática, impossível. 
O material de Gyropaigne brasiliensis C. Bicudo \& D. Bicudo foi coletado do plâncton do hidrofitotério, um ambiente extremamente rico em material orgânico em decomposição.

Finalmente, conforme constou em Bicudo (2010), a despeito de vários trabalhos publicados por B.V. Skvortzov mencionarem o depósito do material examinado no Herbário Científico do Estado "Maria Eneyda P. Kauffmann Fidalgo" (SP), tal fato jamais ocorreu. Não é demais repetir ainda uma vez que o referido profissional mantinha vivos os materiais que coletava, em cultivos bastante incipientes, do tipo soloágua, em sua própria sala de trabalho, à temperatura e luz ambiente, sem os tocar por 10-12 dias. Após esse tempo, os materiais eram examinados ao microscópio. Decorrido ainda mais tempo, a água nesses 'cultivos' fatalmente secava pela falta de manutenção, perdendo-se os materiais neles contidos. Nesta condição, os frascos que continham os 'cultivos' eram lavados pela necessidade de mais recipientes para novos 'cultivos'. Os materiais-tipo de todas as espécies propostas por B.V. Skvortzov jamais foram, por isso, depositados em herbário. No caso específico dos representantes das formas não-pigmentadas das Euglenaceae, acrescente-se que tampouco os materiais são passíveis de fixação e consequente preservação.

Chave geral

1. Célula elipsóide assimétrica

. (Gyropaigne) G. brasiliensis

1. Célula fusiforme, quase acicular ou lunada

2. Célula fusiforme, quase acicular

$$
\text { (Acusmonas) *A. pluvialis }
$$

2. Célula lunada .... (Menoidium) $*$ M. pellucidum

\section{Agradecimentos}

O autor é imensamente grato ao CNPq, Conselho Nacional de Desenvolvimento Científico e Tecnológico pelo financiamento parcial desta pesquisa (Processo n 303876/2004-2).
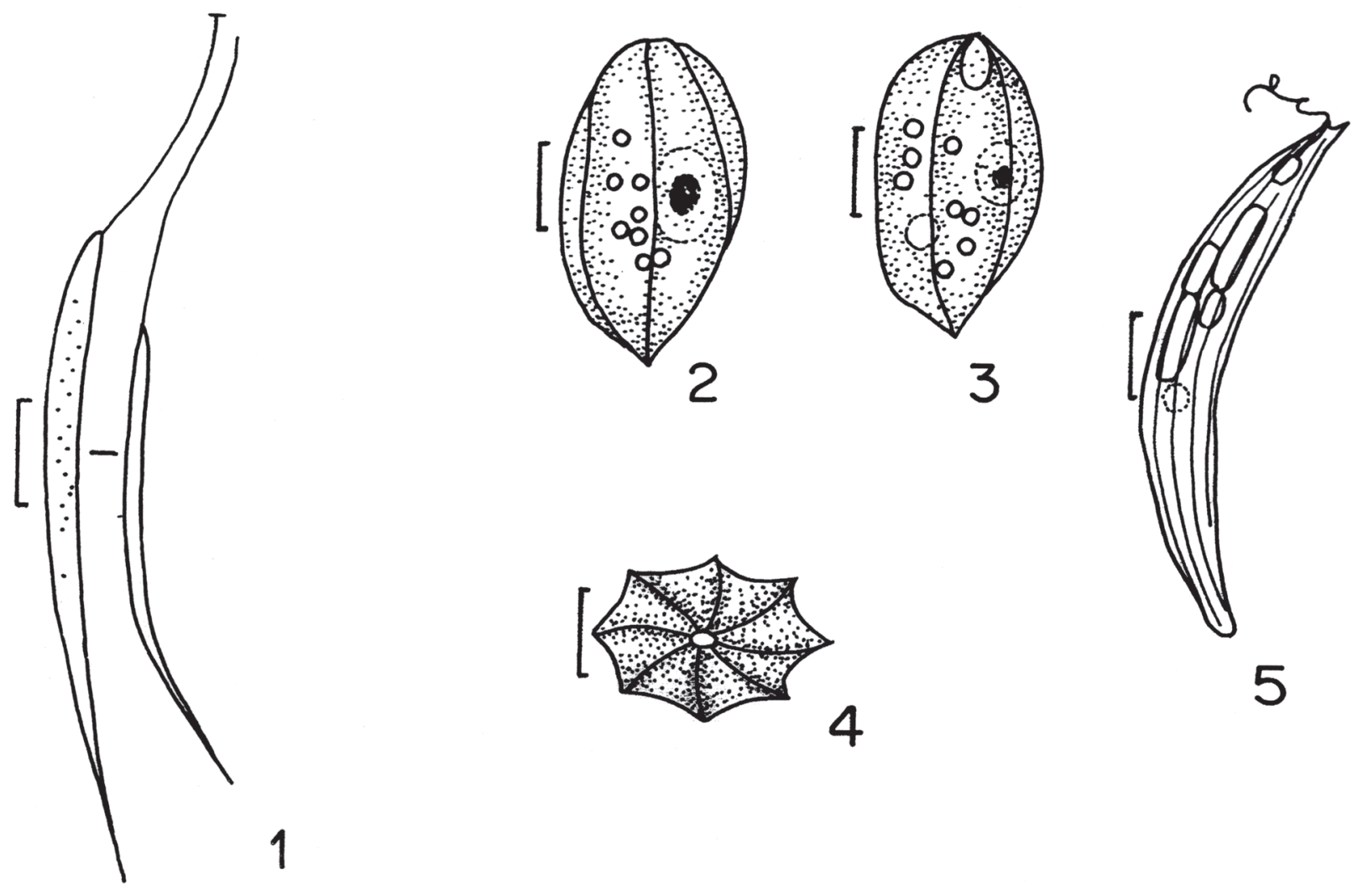

Figuras 1-5. Euglenaceae não-pigmentadas do PEFI. 1. Acusmonas pluvialis (Skvortzov 1969). 2-4. Gyropaigne brasiliensis (Bicudo \& Bicudo 1987). 4. Seção transversal da célula. 5. Menoidium pellucidum (Bicudo \& Menezes 2006). Barras das escalas $=10 \mu \mathrm{m}$.

Figures 1-5. Non-pigmented Euglenaceae of PEFI. 1. Acusmonas pluvialis (Skvortzov 1969). 2-4. Gyropaigne brasiliensis (Bicudo \& Bicudo 1987). 4. Cell transverse section. 5. Menoidium pellucidum (Bicudo \& Menezes 2006). Scale bars $=10 \mu \mathrm{m}$. 


\section{Literatura citada}

Bicudo, C.E.M. 2010. Criptógamos do Parque Estadual das Fontes do Ipiranga, São Paulo, SP. Algas 27: Euglenophyceae (família Peranemaceae). Hoehnea 37: 383-402.

Bicudo, C.E.M. \& Bicudo, D.C. 1987. Some new and rare Euglenophyceae from the State of São Paulo, southern Brazil. Acta Botanica Brasilica 1: 43-48.

Bicudo, C.E.M. \& Menezes, M. 2006. Gêneros de algas de águas continentais do Brasil: chave para identificação e descrições. 2 ed. RiMa Editora, São Carlos.

Bourrelly, P. 1985. Les algues d'eau douce: initiation à la systématique: les algues vertes. v. 1. 2 ed. Éditions N. Boubée \& Cie, Paris.
Huber-Pestalozzi, G. 1955. Euglenophyceae. In: G. HuberPestalozzi (org.), Das Phytoplankton des Süßwassers: Systematik und Biologie. E. Schweizerbart'sche Verlagsbuchhandlung, Stuttgart. v. 16, pt. 3, pp. 1 - 606, tab 1 - 104

Leedale, G.F. 1967. Euglenoid flagellates. Prentice-Hall, Englewood Cliffs.

Skvortzov, B.V. 1958. New and rare Flagellatae from Manchuria, eastern Asia. Phillipine Journal of Science 86: 139-202.

Skvortzov, B.V. 1969. New and little known genera of colourless flagellates of Fam. Astasiaceae, Euglenophyceae recorded in 1954-1968 from N.E. China and Brasil. Quarterly Journal of the Taiwan Museum 22: 223-239. 